Estuarine, Coastal and Shelf Science

February 2018, Volume 201, Pages 95-104

http://dx.doi.org/10.1016/i.ecss.2015.12.009

http://archimer.ifremer.fr/doc/00301/41213/

(c) 2015 Elsevier Ltd. All rights reserved.

\title{
Using a spatially structured life cycle model to assess the influence of multiple stressors on an exploited coastal- nursery-dependent population
}

\author{
Archambault B. ${ }^{1,2}$, Rivot E. ${ }^{1}$, Savina-Rolland Marie ${ }^{3}$, Le Pape Olivier ${ }^{1, *}$
}

${ }_{1}^{1}$ Agrocampus Ouest, UMR 985 ESE Ecologie et santé des écosystèmes, F-35042 Rennes, France

${ }^{2}$ AgroParisTech, F-75005 Paris, France

${ }^{3}$ IFREMER, 150 Quai Gambetta, B.P. 699, Cedex 62321 Boulogne/Mer , France

* Corresponding author : Olivier Le Pape, email adress : Olivier.Le.Pape@agrocampus-ouest.fr

\begin{abstract}
:
Exploited coastal-nursery-dependent fish species are subject to various stressors occurring at specific stages of the life cycle: climate-driven variability in hydrography determines the success of the first eggs/larvae stages; coastal nursery habitat suitability controls juvenile growth and survival; and fisheries target mostly adults. A life cycle approach was used to quantify the relative influence of these stressors on the Eastern English Channel (EEC) population of the common sole (Solea solea), a coastal-nurserydependent flatfish population which sustains important fisheries. The common sole has a complex life cycle: after eggs hatch, larvae spend several weeks drifting in open water. Survivors go on to metamorphose into benthic fish. Juveniles spend the first two years of their life in coastal and estuarine nurseries. Close to maturation, they migrate to deeper areas, where different subpopulations supplied by different nurseries reproduce and are exploited by fisheries. A spatially structured age-and stagebased hierarchical Bayesian model integrating various aspects of ecological knowledge, data sources and expert knowledge was built to quantitatively describe this complex life cycle. The model included the low connectivity among three subpopulations in the EEC, the influence of hydrographic variability, the availability of suitable juvenile habitat and fisheries. Scenarios were designed to quantify the effects of interacting stressors on population renewal. Results emphasized the importance of coastal nursery habitat availability and quality for the population renewal. Realistic restoration scenarios of the highly degraded Seine estuary produced a two-third increase in catch potential for the adjacent subpopulation. Fisheries, however, remained the main source of population depletion. Setting fishing mortality to the maximum sustainable yield led to substantial increases in biomass $(+100 \%)$ and catch $(+33 \%)$ at the EEC scale. The approach also showed how climate-driven variability in hydrography is likely to interact with human pressures, e.g., overfishing increased the sensitivity to unfavorable conditions. Our results provided insights into the dynamics of numerous exploited coastal-nursery-dependent species while paving the way toward more robust advice for sustainable management of these resources.
\end{abstract}

Keywords : Life cycle model, spatial processes, metapopulation, coastal nursery habitat degradation, fishing, Solea, multiple stressors, scenarios 


\section{Introduction}

Marine fish populations are under the influence of multiple environmental and anthropogenic pressures (Halpern et al., 2008). Hydrographic variability (Lehodey et al., 2006), climate cycles (Francis et al., 1998) and long-term climate change (Brander, 2007) impact fish populations. The increasing concentration of human activities along coastal waters affects the quality of essential fish habitat (especially coastal and estuarine ecosystems; Halpern et al., 2008), through physical destruction and pollution (Beck et al., 2001; Peterson et al., 2003). Finally, fisheries (Christensen et al., 2003) affect populations through fishing mortality as well as indirect consequences, such as the reduction of genetic variability linked to selection pressure and the related demographic changes (Conover, 2007) and the perturbations of habitat structure (Turner et al., 1999). These stressors have their respective highest impact at different stages of the life cycle. Climate-driven hydrographic variability controls the success of eggs/larval development and survival (Bakun, 1996), i.e., early stages recruitment success. Habitat availability and quality mostly impacts the critical growth and development phase of juveniles, especially for Coastal-Nursery-Dependent species (CND; i.e., species for which nearshore habitat serves as a nursery for juveniles and contributes disproportionately to the size and numbers of adults relative to other juvenile habitats; Gibson, 1994; Beck et al., 2001). Fishing targets mostly adults (Hilborn, 2011).

Quantifying the impact of these stressors on population dynamics and renewal can offer insights on the ecology of populations needed to support sustainable management schemes. A considerable number of studies addressed the impact of each of these stressors individually. A large body of work has focused on the consequences of climate variability on early stages (review in Houde, 2008). The impact of habitat suitability on juveniles also has been well studied (Brown et al., 2000; Lindholm et al., 2001), especially for CND species (Beck et al., 2001; Vasconcelos et al., 2014). The assessment of fishing impacts on populations has driven the development of fisheries models in the last century (Beverton and Holt, 1957; Hilborn and Walters, 1992) and their wide use for stock assessment (Hilborn, 2011). However, life cycle approaches integrating impacts of these multiple stressors all along the life cycle remain rare. Also, less attention has been paid to the quantitative assessment of how the spatial structure of populations and patterns of connectivity along the life cycle interact with spatially structured stressors (Cianelli et al., 2013) such as coastal nursery habitat degradation (Rabalais, 2015) or spatially non-homogenous fishing effort.

The common sole (Solea solea, L.) population in the Eastern English Channel (EEC, Fig. 1) is an ideal case study (Riou et al., 2001) to quantitatively assess the relative influence of various stressors on fish population dynamics. In the EEC, pelagic larval stages successfully transported to coastal areas (Rochette et al., 2012) metamorphose and settle to the shallow-water demersal habitats of coastal and estuarine nursery grounds (Rochette et al., 2010) before moving to deeper areas when reaching adult stages oduce (Horwood, 1993). The low connectivity along the successive stages of the life cycle (i.e., (i) larval retention within spawning regions (Rochette et al., 2012); (ii) spatial segregation of juveniles inside separated coastal and estuarine nursery grounds (Coggan and Dando, 1988; Riou et al., 2001); and (iii) limited individual movement at the adult stages (Kotthaus, 1963)) suggests a metapopulation structure with partial segregation of three subpopulations (UK, East FR, and West FR; Fig. 1). Multiple pressures impact the life cycle in the EEC: climate-driven hydrographic variability on survival of pelagic eggs and larvae (Rochette et al., 2012); substantial habitat loss and degradation of the quality of remaining habitats in coastal and estuarine nursery grounds, especially in the Seine 
estuary (Le Pape et al., 2007; Rochette et al., 2010); high fishing mortality at adult stages (i.e., higher than fishing mortality at Maximum Sustainable Yield; $F_{M S Y}$; ICES, 2013). Based on the modelling framework developed by Rochette et al. (2013), Archambault et al. (in review) have built an integrated spatially structured life cycle model for this population in a Bayesian hierarchical modelling framework (Parent and Rivot, 2012), which proved successful in integrating ecological knowledge, heterogeneous sources of data and expert information. In this present work, the model structure and parameterization proposed by Archambault et al. (in review) was used to run simulations based on scenarios designed to assess the relative influence of the different stressors (i.e., hydrographic variability; quantity/quality of nursery habitat; fisheries exploitation) on the survival during the life cycle and the productivity of the population. This study not only evaluated the respective impact of each of these stressors on the life cycle but also examined their possible interactions. Because no consistent data exist to quantify adult-mediated connectivity (Archambault et al., in review), the model was also used to qualitatively assess how the patterns of adult connectivity among the three subpopulations may interact with the influence of the different stressors.

\section{Materials and methods}

\subsection{Operating model for the population dynamics}

The spatial structure of the EEC sole populations (Fig. 1) was based on the three subpopulations previously identified (UK, East FR and West FR; Archambault et al., in review). Five coastal and estuarine nursery grounds, each associated with one of the three subpopulations (Veys and Seine in West FR, UK West and Rye in UK, Somme in East FR; Fig. 1) were considered. The life cycle model was based on an extensive data set presented in detail by Archambault et al. (in review) which included: (i) the outputs of a biophysical larval drift model which provided annual egg and larval survival and allocation from spawning areas to the five nursery sectors; (ii) annual juvenile (ages 0 and 1) abundance indices over the five nursery sectors; (iii) annual catch-at age and abundance indices from the ICES stock assessment working groups, also defined at the scale of the three subpopulations using ancillary data. The main processes and key parameters of the life cycle are given in the following model structure (Fig. 2, with matching numbering). All parameters were derived from the Bayesian fitting procedure developed by Archambault et al. (in review).

(1) Each year (subscript y from 1982 to 2007), eggs and larvae were transported from each of the three spawning areas (subscript $r$ from 1 to 3 ) and eventually died or settled in one of the 5 identified nursery sectors (subscript $\mathrm{i}$ from 1 to 5). The probability for an egg from an egg pool $\omega_{\mathrm{y}, \mathrm{r}}$ to reach a nursery $\mathrm{i}$ was given by an allocation and survival matrix Key $\mathrm{y}_{\mathrm{r}, \mathrm{r}, \mathrm{i}}$. Values of the allocation and survival matrix were sampled in a time series of 26 years (1982-2007) available from previous work (Rochette et al. (2012), upgraded by Savina et al., in review; see Archambault et al., in review). The number of larvae $\mathrm{L}$ reaching a given nursery sector at year $\mathrm{y}$ was calculated from Eq. 1:

Eq. 1

$$
L_{y, i}=\sum_{r} \omega_{y, r} \times \operatorname{Key}_{y, r, i}
$$

Note that, given the values of $K e y_{y, r, i}$, eggs-and-larvae-mediated connectivity among the three subpopulations was extremely low (Fig. 2; Rochette et al., 2012).

(2) Settled larvae experienced compensatory density-dependent post-settlement mortality (Iles and Beverton, 2000; Archambault et al., 2014) over nursery sectors between settlement (late spring) and the end of the growth stage of the age-0 juveniles (early September). The number of age-0 juveniles in the nursery $i$ in September of year $y, N_{0, y, i}$, was modelled by a Beverton-Holt relationship with lognormal process errors (Eq. 2). 
Eq. $2 \quad N_{0, y, i}=\frac{\alpha_{i} \times L_{y, i}}{1+\frac{\alpha_{i}}{\mathrm{~K}_{i} \times \operatorname{Surf}_{i}} \times L_{y, i}} \times e^{\epsilon_{0, y, i}}$

where $K_{i}$ is the nursery-specific carrying capacity per units of surface area (Surf $f_{i}$ the nursery sector surface area) and $\alpha_{i}$ the maximum survival rate.

(3) The natural mortality rate of age- 0 juveniles in nursery sectors was set to $M_{0}$ from September until they reach age- 1 in January, then to $M_{1}$ for age- 1 juveniles until they reached age- 2 .

(4) Age-2 fish were assumed to leave the nurseries at the beginning of year $y+2$. Two structural model hypotheses $S_{0} / S_{1}$ were considered (Fig. 2; Table 1). In the baseline structural hypothesis $S_{0}$, there was no inter-regional connectivity at age- 2 among the three subpopulations. As a consequence, the number of age-2 fish in the subpopulation $r$ at the beginning of year $y+2$ only resulted from the age-1 juvenile of year $y+1$ from the nurseries associated locally with subpopulation $r$ (Fig. 1). In the alternative structural hypothesis $S_{1}$, a connectivity induced by the mixture of age- 2 fish among the three subpopulations was introduced (Table 1). Age-1 juvenile in nursery $i$ contributed mostly (80\%) to its associated subpopulation $r$, the remaining contributed equally (10\% each) to the two other subpopulations. Those values were set arbitrarily to qualitatively assess the impact of considering age2-mediated migration. In both structural hypotheses, no exchange among the three subpopulations was considered after age-2. Although quantitatively very limited under the structural hypothesis $S_{0}$ (because they only resulted from the low larval-drift-mediated connectivity among the three subpopulations; Rochette et al. 2012), exchanges could not be dismissed. As a consequence, the population dynamics of each of the three subpopulations could not be considered as independent under both structural hypotheses.

(5) The adult population (and its 3 subcomponents) consisted of 14 age classes between age- 2 and age15 (subscript $a$ from 2 to 15 in the following), with each a natural mortality rate $M_{a}$ and fishing mortality rates $F_{a, y, r}$ and lognormal random noise (Eq. 3). All remaining fish were assumed to die at age-15.

Eq. $3 \quad N_{a+1, y+1, r}=N_{a, y, r} \times e^{-\left(M_{a}+F_{a, r}, y\right)} \times e^{\epsilon_{a, y, r}}$

Catches-at-age (in number) in each subpopulation were defined following the standard equation:

Eq. 4

$$
C_{a, y, r}=N_{a, y, r} \times \frac{F_{a, y, r}}{F_{a, y, r}+M_{a}} \times\left(1-e^{-\left(M_{a}+F_{a, r, y}\right)}\right)
$$

Total catch (C) in weight for each subpopulation were derived from catches in number, accounting for weights-at-age, and then summed for age 2 to 15 .

(6) Spawning stock biomass ( $S S B$; sum for age 2 to 15 ) in each subpopulation contributed yearly to the local egg pools $\omega_{y, r}$, based on numbers at age $N_{a, y, r}$, weights-at-age, female proportion, fecundity and maturity.

\subsection{Simulations and parameterization}

For each scenario (described later), Monte Carlo simulations were run to integrate over both process' errors and parameters' uncertainty. For a given set of parameters, the population dynamics were simulated over 200 years including process error (i.e., interannual variability in survival from larvae to age- 0 , of juveniles and of adults). In all scenarios, the ergodic (equilibrium) state was assumed to be reached after 100 years of simulation and the process error was estimated by considering the distribution of the results between year 101 and 200. Parameters uncertainty was fully integrated by using the Bayesian posterior distribution probability around parameters derived from Archambault $e t$ 
al. (in review), which describe uncertainty on parameter estimates together with the statistical covariance structure among the parameters (Punt and Hilborn, 1997; Parent and Rivot, 2012). In practice, the simulation procedure was repeated 1,500 times with 1,500 sets of parameters directly drawn in the joint posterior distribution of model parameters provided by Archambault et al. (in review).

\section{Scenarios on environmental and anthropogenic pressures}

Realistic scenarios of different magnitudes of the main stressors (Table 2) were explored to analyse marginal and combined effects of stressors for the two structural model hypotheses (spatial structures of adults $S_{0}$ and $S_{1}$; Table 1 ).

\section{Interannual hydrographic variability in the EEC}

To our best knowledge, there is no downscaled (high resolution) products available projecting how climate change scenarios will impact on hydrographic transport dynamics in the EEC. Therefore, the analysis was carried out by considering the influence of climate variability only, without any prospective trend. The influence of the interannual variability of hydrographic conditions on eggs and larvae drift and survival was assessed by running the model with an allocation and survival matrix considered constant during the 200 years of the simulation time, fixed to one of the 26 configuration available from the historical reconstruction (1982-2007).

\section{Juvenile habitat}

Scenarios of juvenile habitat restoration focussed on the Seine estuary only. Indeed, no other nursery sectors have gone through equivalent degradation, including dramatic reduction in both size and quality (Le Pape et al., 2007). The Seine estuary has undergone notable morphological changes in the past century through channel dredging and construction of dikes and harbours (Rochette et al., 2010). This has led to a strong reduction of essential nursery habitat for sole and other flatfishes, and especially shallow muddy areas. Rochette et al. (2010) evaluated the habitat loss (i.e., surface area only) to be responsible for a $42 \%$ decrease of the nursery capacity of the Seine estuary since the early $19^{\text {th }}$ century. Accordingly, a first habitat restoration scenario where the Seine estuary is restored to its early $19^{\text {th }}$ century surface area was considered, modelled by increasing $\operatorname{Surf}_{i}$ for the Seine estuary (Eq. 2) by a factor of 1.724. In addition to surface area loss, the Seine estuary is subject to strong chemical contamination causing reductions in habitat quality (Gilliers et al., 2006; Courrat et al., 2009). The density-independent component of the larvae-to-age-0 survival ( $\alpha$ parameter of the Beverton-Holt equation in Eq. 2, calculated in Archambault et al. (in review) had the lowest value in the Seine estuary ( $83 \%$ lower than the median of the four other sectors). To evaluate a potential restoration of habitat quality and its impact on the critical settlement phase, the value of the parameter $\alpha$ for the Seine estuary was increased to the median of the four other nursery sectors. Last the conjunction of both surface area and habitat quality restoration was simulated. Only the equilibrium state of the system (once equilibrium is reached) was considered, not the kinetics of the restoration. Thus, (unrealistic) immediate complete restoration of surface area and habitat quality was simulated.

\section{Fishing pressure}

The effect of fishing pressure was assessed by exploring a wide range of fishing mortality rate ( $F$ from 0 to 1.5 ; Table 2) equal or not among the three different subpopulations to explore alternative spatial fishing scenarios. For all configurations, the population was simulated with constant $F$ in time during 200 years to reach an equilibrium state. Results obtained by exploring a wide range of $F$ were used to empirically construct the equilibrium curve relating Catch $(C)$ and Spawning Stock Biomass $(S S B)$ at equilibrium, therefore enabling the estimation of management reference points such as $B_{M S Y}, F_{M S Y}$ and $C_{M S Y}$ (i.e., at the Maximum Sustainable Yield; widely used key indicators of the stock status and management reference points; Hilborn and Walters, 1992). 
Because the population dynamics of each of the three subpopulations were interconnected for both model configurations, reference equilibrium points for each subpopulation $r$, denoted $B_{M S Y, r}, F_{M S Y, r}$ and $C_{M S Y, r}$, were estimated conditionally by fixing the fishing pressure for the two other subpopulations (Table 2) at their reference value (i.e., average values in the last 4 years (2007-2011); $F_{\text {WestFR }}=0.16, F_{U K}=0.44, F_{E a s t F R}=0.8$; Archambault et al., in review). An equilibrium point at the scale of the whole EEC (i.e., global $M S Y$ ) was estimated empirically by exploring all possible combinations of $F_{W e s t F R}, F_{U K}, F_{E a s t F R}$ within the explored range.

\section{Simulation plan and indicators}

Reference values were defined from the "status quo" scenario $S c e_{r e f}$, which considers average hydrographic conditions (i.e., average survival and allocation matrix of eggs/larvae), no modification of nursery habitat (i.e., constant Seine $\operatorname{Surf}$ and $\alpha$ ) and local fishing pressure $F_{r}$ set at their reference value. To isolate the marginal impact of each stressor (hydrographic variability, habitat, fishing), the modality of one stressor (Table 2) was marginally modified while the two remaining stressors were kept at the reference value. Then, variations of different stressors were combined to estimate their interactions (Table 2). The simulation plan finally consisted in 794 scenarios combining different modalities for each stressor.

For each simulation, we monitored the stock spawning biomass and catch at equilibrium obtained for each subpopulation (denoted $S S B_{e q, r}$ and $C_{e q, r}$ ). For each indicator, the relative percentage of gain/loss between the explored scenario $S c e$ and the reference scenario $S_{c e} e_{r e f}$ (Eq. 5) was calculated.

Eq. 5

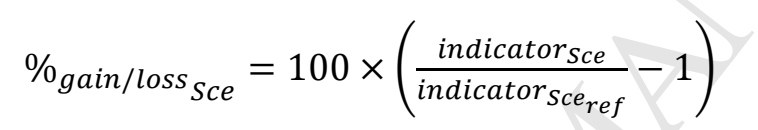

Last, the scenario maximizing $C_{e q, r}$ in all simulated scenarios ("best" scenario $S c e_{\text {best }}$, Table 2) was identified.

\section{Results}

For clarity, the mean estimates of indicators obtained under the baseline structural hypothesis $S_{0}$ (i.e., no age-2-mediated connectivity among subpopulations) are provided. The impact of considering the alternative structural hypothesis $S_{1}$ (i.e., partial age-2-mediated connectivity among subpopulations) is then explored.

\subsection{Baseline model configuration $S_{0}$}

\section{Reference scenario}

The reference scenario $S c e_{\text {ref }}$ led to mean local $S S B$ at equilibrium of 7,565, 4,060 and 2,305 $\mathrm{t}$ for West FR, UK and East FR subpopulations, respectively, and of 13,930 t at the EEC scale (Fig. 3; with the associated uncertainty linked to both process error and parameters uncertainty). Catch-atequilibrium for each subpopulation was 1,065, 1,330 and 1,140 t for West FR, UK, and East FR, respectively, and 3,535 $\mathrm{t}$ at the EEC scale. If not mentioned otherwise, indicators were compared to this reference scenario (Table 2).

Uncertainty in indicators, estimated from the combination of both process error and parameters uncertainty, was quite high (Fig. 3). However, uncertainty remained the same for all scenarios and its effects on the indicators of relative gain/loss of SSB and catch did not affect the ranking of scenarios. 
Thus, for clarity purposes, scenarios were further compared using only the mean of indicators on the 1500 sets of parameters run.

\section{Marginal impacts of stressors}

Hydrographic variability

A range of high/low survival and variable allocation patterns for the five nurseries was represented within this 26 years' time series. However, the differences in larval survival among regions were moderate (i.e., years with low survival of eggs and larvae at the scale of the EEC were also years of low survival for each subpopulation). The hydrographic variability during the 26 years between 1982 and 2007 and the related fluctuations in larval settlement success on nursery grounds induced a maximum range of variation of $42 \%$ of the SSB at the scale of the EEC (Table 3). As illustrated by year 1991 (i.e., when the worst conditions of larval survival were observed), conditions encountered for years with poor larval survival led to substantially reduced SSB.

\section{Habitat restoration}

Restoration of the surface area and the quality of nursery habitat in the Seine estuary had a substantial impact on the SSB of the West FR subpopulation, with an comparable positive effect on population abundance and catch at equilibrium (42\% increase of catch in the scenario of capacity restoration, $13 \%$ increase in the habitat quality restoration scenario and 66\% increase with combined restoration; Table 3; Fig. 4). Without exchanges among the subpopulations, East FR and UK, subpopulations were not affected by habitat restoration in the Seine estuary. However, when averaged at the scale of the whole EEC population, habitat restoration translated into significant increase in both SSB and C (Table 3).

Fishing pressure

For each subpopulation, when considering the fishing pressure of other subpopulations fixed at their reference values, the conditional $M S Y$ is estimated at $F_{r}=0.2$. Because the drift-mediated connectivity at larval stage was too low to have a visible impact on the population dynamics, the MSY at the scale of EEC (obtained by testing all possible combination of $F_{r}$ ) was also found when the three $F_{r}=0.2$. Setting fishing mortalities to 0.2 for all subpopulations led to $C_{M S Y}$ of $4,700 \mathrm{t}$ and $S S B_{M S Y}$ of $24,300 \mathrm{t}$ at the scale of the whole EEC, an increase of $33 \%$ in catch and $100 \%$ in SSB (Table 3) with regards to the reference situations (estimated $F$ over the past 4 years). $S S B_{M S Y}$ was at about a third of $S S B_{F=0}$, while $S S B_{e q}$ at current levels of fishing was at about a sixth. Results at the scale of the EEC masked strong differences among the subpopulations. The West FR indicators were not affected by adjusting $F$ to $M S Y$ because the fishing mortality was already (at the reference level) close to 0.2. By contrast, the gain of biomass and catch at equilibrium was high for the UK $(+146 \%)$ and the East FR $(+362 \%)$ subpopulations when they were exploited at local $F_{M S Y}$ (Table 3), as those two subpopulations were overexploited in the reference scenario.

\section{Combined impacts}

Hydrographic variability $\times$ Fishing

Increasing the fishing pressure simultaneously on all subpopulations dramatically increased the influence of the between-year variability stemming from differences in hydrographic conditions (Fig. 5). The years with unfavourable hydrography had a more pronounced, negative effect under overfishing conditions.

\section{Hydrographic variability $\times$ Habitat}

No combined effect of habitat and climate was identified; the impact of annual hydrographic conditions on $S S B$ and $C$ was not affected by the different habitat scenarios. 
Fishing $\times$ Habitat (anthropogenic pressures which can be managed)

When habitat restoration only concerned the surface area of the nursery habitat, the gain in the catch at equilibrium with respects to the habitat reference scenario was always the same, whatever the fishing pressure (Fig. 6). The absolute gain in $S S B$ depended on $S S B / F$ but the relative gain of larger nursery grounds remained stable, at about $42 \%$. By contrast, when the maximum survival rate of early juveniles was enhanced, the resilience to fishing pressure (i.e., decreased larval inputs) increased (i.e., the relative gain in catch at equilibrium increased with fishing pressure; Fig. 6).

\section{The ideal world: MSY for restored nurseries and the "best" larval settlement}

The "best" scenario, combining hydrographic conditions maximizing survival during the larval drift (year 1993) with restored surface area and habitat quality in Seine estuary and all $F$ set at $F_{M S Y}$, led to a $140 \%$ increase in SSB at the scale of the EEC and to a $63 \%$ increase in catch at equilibrium, compared to $S c e_{\text {ref }}$ (Table 3).

\subsection{Impact of adult-mediated connectivity}

Introducing exchanges among subpopulations affected the dynamics of the whole EEC system and resulted in a complex metapopulation dynamics characterized by multiple spatial interactions. Overall, the effects of stressors with a direct local impact (habitat restoration, fishing pressure) were locally dampened and spread to the whole EEC when introducing exchanges at age-2.

As sizes at equilibrium were different among the subpopulations, introducing homogeneous emigration/immigration rates between the subpopulations did not lead to homogeneous emigration/immigration in terms of fish numbers. The subpopulation with the lowest $S S B_{e q}$ benefited from the immigration of fish while subpopulations with higher $S S B_{e q}$ lose individuals (source-sink dynamics; Hanski, 1999). When considering stressors at their baseline reference levels, introducing exchanges led to a $+9 \%$ variation of $S S B_{e q}$ in the West FR, $-1.5 \%$ in the UK and $-4.5 \%$ in the East FR. Overall, this resulted into a $+3.5 \%$ variation at the EEC scale, related to the supply of fish moving toward the less fished area (West FR), with a better survival at adult stage.

While local fishing pressure had only local effects under the hypothesis $S_{0}$ (no inter-regional migration), fishing pressure on one subpopulation impacted the other when introducing connectivity $\left(S_{1}\right)$. For instance, increasing $F$ in East FR decreased the abundance and the level of catch in UK and West FR (Fig. 7). The global $M S Y$ under $S_{1}$, estimated by simulating all combinations of $F_{\text {WestFR }}, F_{U K}, F_{\text {EastFR }}$, did not change by comparison with $S_{0}\left(4,700 \mathrm{t}\right.$, all $F_{r}$ at 0.2$)$, although subpopulations contributed differently to this total catch $\left(S_{0}: 22.5 \% ; 36.5 \% ; 41 \%\right.$ and $\mathrm{S}_{1}: 26 \% ; 35.5 \%$; $38.5 \%$ for West FR, UK and East FR, respectively).

Restoring the habitat in Seine estuary under hypothesis $S_{0}$ increased local $C_{M S Y, W e s t F R}$ without impact on other subpopulations (Table 3). With inter-regional migration $\left(S_{1}\right)$, the gain of restoring habitat in the Seine estuary was slightly lower than under $S_{0}$ for the West FR $(+50 \% /+66 \%)$, but spread over other subpopulations ( $+13 \%$ for UK and $+5 \%$ for East FR; Fig. 8 ).

\section{Discussion}

Our approach combined ecological knowledge and parameterization derived from a Bayesian inference procedure (Archambault et al., in review) with simulations based on realistic scenarios. This approach assessed the marginal and combined impacts of the main stressors affecting the different life stages of an exploited CND population, while providing more general insights on spatial management considerations for CND species and the related fisheries. 


\subsection{Weaknesses of the approach and challenges in the design of realistic scenarios}

Our simulation approach relied on a hierarchical Bayesian age-and-stage-structured life cycle model developed by Archambault et al. (in review), which integrated the best available knowledge and data. The operating model used for simulations related to the baseline hypothesis $S_{0}$ was fully consistent with the model developed by Archambault et al. (in review) and allowed for integrating process errors and parameters uncertainty. As with any modelling approach, a body of assumptions had to be formulated. Many parameters were considered constant, namely biological parameters (e.g., juvenile to adult natural mortality, fecundity, weight-at-age) and exploitation parameters (e.g., fisheries selectivity). The consequences of these preliminary choices were analysed during the development of the model and have been thoroughly discussed by Rochette et al. (2013) and Archambault et al. (in review).

To our knowledge, the present approach was the first one to assess the combined consequences of hydrographic variability, coastal and estuarine nursery habitat degradation and fishing pressure on the life cycle of an exploited marine fish population. The formulation of a reference scenario and realistic alternatives was challenging: (i) simulating a large range of fishing pressures enabled the investigation of various states of the system, including the current situation, and the estimation of sustainable target reference points (MSYS and the related biomasses and fishing mortalities; Hilborn, 2011); (ii) realistic habitat restoration scenarios were considered. They were based on the reversion of historical degradation which happened in the Seine estuary, and caused the losses of estuarine habitats and the low quality of the remaining nursery grounds (Le Pape et al., 2007; Rochette et al., 2010); (iii) future climate scenarios were not available and the 26-year time series of hydrographic conditions was used as a credible range of variability. Strong assumptions were made to define these scenarios (e.g., constant (i) hydrographic conditions, (ii) nursery surface area and quality, or (iii) local exploitation levels throughout each simulation). Also, the transient (non-equilibrium) dynamics during the first 100 years of each simulation were not analysed, the focus being on the equilibrium state.

Another challenge lay in defining the structural hypotheses to explore the consequences of uncertainties in the spatial structure of the adult fraction of the population. Indeed, while the nomigration scenario was based on ecological clues suggesting a limit connectivity among adult fractions (Archambault et al., in review), it is unlikely that zero migration truly occurs. The introduction of moderate migration resulted in a complex meta-population system characterized by multiple spatial interactions. Migration dramatically increased the complexity of the system, the associated uncertainty and data requirements (Archambault et al., in review). While this was not investigated here, the dynamics of this system are obviously highly sensitive to the magnitude and the direction of these migrations. Moreover, these migrations could also happen at any time of the adult stage rather than only at the age-2, as in our model. A better estimation of migration coefficients (i.e., using markrecapture data, based on natural (Cuveliers et al., 2010) or artificial (Rijnsdorp and Pastoors, 1995; Darnaude and Hunter, 2008) markers, and using integrated modelling approaches (Goethel et al., 2014), would certainly improve the realism of model outputs.

This approach of combining a life cycle model with scenarios required a large amount of data and is not easily applicable to other, less data-rich case studies. However, the approach could be extended to other sole populations for which similar spatial information on the different life stages (larval drift, juvenile abundance, adult biomass and catch) is available and could also be transferred to other populations of well-studied CND species (e.g., the common plaice, Pleuronectes platessa; van de Wolfsharr et al., 2011). Moreover, qualitative conclusions are most likely extendable to other exploited CND species. 


\subsection{Assessing the impact of different stressors along the life cycle}

For most exploited marine fish populations, fisheries are identified as the main source of depletion (Jackson et al., 2001). The current levels of fishing mortality for two of the subpopulations of the EEC sole are higher than $F_{M S Y}$, and the population's abundance at $M S Y$ would still be highly depleted (by a factor of 3) compared to the pristine state. This is common in most marine fish populations, which can sustain relatively high levels of exploitation due to the nature of marine fish reproductive strategies (Adams, 1980).

In addition to fishing pressure, our results highlighted the potential effectiveness of measures aiming at improving or preserving the carrying capacity of juvenile habitat to increasing the size of the adult population. Indeed, this habitat improvement may be as or more beneficial than regulating fishing effort on adults (Levin and Stunz, 2005; van de Wolfshaar et al., 2011; Hugues et al., 2015). The common sole is a CND species (Riou et al., 2001; Le Pape et al., 2003) and the success of its life cycle is highly dependent on restricted coastal and estuarine nurseries. The restoration of habitats in the Seine sector would increase $S S B$ at the scale of the whole EEC population $(+36 \%)$ with a large gain at the local scale (Western French coasts), especially at high fishing levels. If the level of degradation of the other coastal nurseries in the EEC had been lower than in the Seine estuary for the two last centuries, restoring coastal habitats along the whole EEC shore could nonetheless increase sole SSB in even higher proportion than simulated here.

Considering the current level of exploitation, the variability of hydrographic conditions (as estimated in the historical time series 1982-2007) results in a moderate variability in sole $S S B$. This is a consequence of density-dependent processes during the concentration of juveniles within nurseries with limited carrying capacities, which dampen the variability of larval input (Iles and Beverton, 2000; Archambault et al., 2014; Le Pape and Bonhommeau, 2015). However, when the population size is heavily depleted under high fishing pressure, arrivals of larvae become limiting, increasing the influence of hydrographic variability in transport success (Planque et al., 2010).

In the model, each factor of stress (hydrographic variability, habitat, fishing) was schematically associated with one specific phase in the life cycle. This was obviously a strong simplification, as some of the factors may impact more than one life stage. For instance, hydrographic conditions may affect the survival of juveniles and adults as well as the fecundity and spawning success of adults (Portner, 2012). Habitat degradation may also influence the survival or the fitness of adult: (i) through delayed effects of the exposition to xenobiotics during juvenile stage in coastal nursery grounds, which can affect future reproduction potential (Adams et al., 1992; Johnson et al., 1998); (ii) in deeper adults feeding and spawning grounds (e.g., impact of sand and gravel extractions; Marchal et al., 2014).

\subsection{Towards integrated spatial management of exploited CND species}

Our study highlights how a better understanding of the spatial functioning of the population may improve management of fishing pressure. The dependence of the recruitment to multiple nurseries, associated with larval retention and low adult-mediated connectivity, results in a meta-population structure in which components may have different dynamics and productivities. Optimal harvesting strategies should ideally account for the spatial structure (Tuck and Possingham, 1994; Spies et al., $2015)$ and should be based on management reference points $\left(e . g ., F_{M S Y}\right)$ defined locally to match the heterogeneity in $S S B$ and productivity among components of the metapopulation. Ignoring the spatial structure (i.e., by setting one single management target for the whole metapopulation) could result in serious local over- (or under-) exploitation (Tuck and Possingham, 1994; Ying et al., 2011; Yau et al., 2014). However, considering adult-mediated connectivity among the different components of the metapopulation greatly increases the complexity of the dynamics. 
In addition to fisheries management, restoration of coastal and estuarine habitats is needed to maintain and restore the large number of coastal dependent fish populations and related fisheries (Seitz et al., 2014). Indeed, this modelling approach showed how the interaction of spatially optimized fishing levels and local habitat restoration measures could synergize to improve population production and spawning stock biomass. Such approach could support decision making in the context of multiple spatial management options (e.g., restoration of coastal nursery surface areas combined with fishing management measures). These combined pressures have to be accounted for to simultaneously manage different factors of stress occurring at different spatial locations and scales. For instance, the present modelling approach shall help decision making in conservation schemes, to prioritize the protection of essential fish habitats (Le Pape et al., 2014) and design coherent marine protected areas (Botsford et al., 2009; Gaines et al., 2010).

Coastal waters are subject to a large number of anthropogenic pressures (Halpern et al., 2008) and these pressures are expected to grow as the human population living in coastal areas increases. Their anthropogenic impacts on estuarine and coastal ecosystems affect critical ecosystem services (Worm et al., 2006), including the provision of coastal nursery habitats (Hugues et al., 2015), facing a 69\% decline worldwide (Barbier et al., 2011). As fishing pressure is high on the large number of other CND species (Seitz et al., 2014), the robust spatial management which accounts for interacting pressures remains a grand challenge. While being based on a specific case study, our approach could be generalized to other exploited flatfish populations (e.g., plaice in the North Sea), and more generally to exploited CND species. CND concerns not only flatfish (Archambault et al., 2014) but a large number of round fish and other marine species (44\% of all ICES advice species rely on coastal habitats, and these $44 \%$ contributed $77 \%$ of the commercial landings of ICES advice species; Seitz et al., 2014).

\section{Acknowledgements}

This work was funded by the EU project Vectors of Change in Oceans and Seas Marine Life, Impact on Economic Sectors (VECTORS). We are grateful to Sophie Pasquier for compiling references. We would especially like to thank Myron Peck, the guest editor, and the two anonymous reviewers for their numerous fruitful suggestions of improvements and their helpful advice.

\section{References}

Adams, P.B., 1980. Life history patterns in marine fishes and their consequences for fisheries management. Fishery Bulletin 78, 1-12.

Adams, S.M., Crumby, W.D., Greeley, M.S., Ryon, M.G., Schilling, E.M., 1992. Relationships between physiological and fish population responses in a contaminated stream. Environmental Toxicology and Chemistry 11, 1549-1557.

Archambault, B., Le Pape, O., Baulier, L., Vermard, Y., Rivot, E., in review. Adults mediated connectivity affects inferences on population dynamics and stock assessment. Fisheries Research.

Archambault, B., Le Pape, O., Bousquet, N., Rivot, E., 2014. Density-dependence can be revealed by modelling the variance in the stock-recruitment process: an application to flatfish. ICES Journal of Marine Science 8, 2127-2140.

Bakun, A., 1996. Patterns in the ocean: ocean processes and marine population dynamics.

Barbier, E., Hacker, S., Kennedy, C., Koch, E., Stier, A., Silliman, B., 2011. The value of estuarine and coastal ecosystem services. Ecological monographs 81, 169-193.

Beck, M.W., Heck Jr, K.L., Able, K.W., Childers, D.L., Eggleston, D.B., Gillanders, B.M., Halpern, B., Hays, C.G., Hostino, K., Minello,T.J., Orth, R.J., Sheridan, P., Weinstein, M.P., 2001. The Identification, conservation, and management of estuarine and marine nurseries for fish 
and invertebrates: A better understanding of the habitats that serve as nurseries for marine species and the factors that create site-specific variability in nursery quality will improve conservation and management of these areas. Bioscience 51, 633-641.

Beverton, R.J.H., Holt, S.J., 1957. On the Dynamics of Exploited Fish Populations. Springer. 552 pp.

Botsford, L.W., Brumbaugh, D.R., Grimes, C., Kellner, J.B., Largier, J., O'Farrell, M.R., Ralston, S., Soulanille, E., Wespestad, V., 2009. Connectivity, sustainability, and yield: bridging the gap between conventional fisheries management and marine protected areas. Reviews in Fish Biology and Fisheries 19, 69-95.

Brander, K.M., 2007. Global fish production and climate change. Proceedings of the National Academy of Sciences 104, 19709-19714.

Brown, S.K., Buja, K.R., Jury, S.H., Monaco, M.E., Banner, A., 2000. Habitat suitability index models for eight fish and invertebrate species in Casco and Sheepscot Bays, Maine. North American Journal of Fisheries Management 20, 408-435.

Christensen, V., Guénette, S., Heymans, J.J., Walters, C.J., Watson, R., Zeller, D., Pauly, D., 2003. Hundred-year decline of North Atlantic predatory fishes. Fish and Fisheries 4, 1-24.

Cianelli, L., Fisher, J., Skern-Mauritzen, M., Hunsicker, M., Hidalgo, M., Frank, K., Bailey, K., 2013. Theory, consequences and evidence of eroding population spatial structure in harvested marine fishes: a review. Marine Ecology Progress Series 480, 227-243.

Coggan, R.A., Dando, P. R., 1988. Movements of juvenile Dover sole, Solea solea (L.), in the Tamar Estuary, South-western England. Journal of Fish Biology 33, 177-184.

Conover, D., 2007. Nets versus nature. Nature 450, 179-180.

Courrat, A., Lobry, J., Nicolas, D., Laffargue, P., Amara, R., Lepage, M., Girardin, M., Le Pape, O., 2009. Anthropogenic disturbance on nursery function of estuarine areas for marine species. Estuarine, Coastal and Shelf Science 81, 179-190.

Cuveliers, E.L., Geffen, A.J., Guelinckx, J., Raeymaekers, J.A.M., Skadal, J., Volckaert, F.A.M., Maes, G.E., 2010. Microchemical variation in juvenile Solea solea otoliths as a powerful tool for studying connectivity in the North Sea. Marine Ecology Progress Series 401, 211-220.

Darnaude, A., Hunter, E., 2008. Coupled use of data storage tags and otolith microchemistry to assess population dispersal and intra-specific diversity in migratory behaviour in North Sea plaice (Pleuronectes platessa L.). Comparative Biochemistry and Physiology A: Molecular \& Integrative Physiology 150, S205-S205.

Francis, R.C., Hare, S.R., Hollowed, A.B., Wooster, W.S., 1998. Effects of interdecadal climate variability on the oceanic ecosystems of the NE Pacific. Fisheries Oceanography 7, 1-21.

Gaines, S.D., White, C., Carr, M.H., Palumbi, S.R., 2010. Designing marine reserve networks for both conservation and fisheries management. Proceedings of the National Academy of Sciences 107, 18286-18293.

Gibson, R.N., 1994. Impact of habitat quality and quantity on the recruitment of juvenile flatfishes. Netherlands Journal of Sea Research 32, 191-206.

Gilliers, C., Le Pape, O., Désaunay, Y., Morin, J., Guérault, D., Amara, R., 2006. Are Growth and density quantitative indicators of essential fish habitat quality? An application to the common sole Solea solea nursery grounds. Estuarine, Coastal and Shelf Science 69, 96-106.

Goethel, D.R., Legault, C.M., Cadrin, S.X., 2014. Demonstration of a spatially explicit, tag-integrated stock assessment model with application to three interconnected stocks of yellowtail flounder off of New England. ICES Journal of Marine Science: 72 (1), 164-177

Halpern, B.S., Walbridge, S., Selkoe, K.A., Kappel, C.V., Micheli, F., D’Agrosa, C., Bruno, J.F., Casey, K.S., Ebert, C., Fox, H.E., Fujita, R., Heinemann, D., Lenihan, H.S., Madin, E.M.P., Perry, M.T., Selig, E.R., Spalding, M., Steneck, R., Watson, R., 2008. A global map of human impact on marine ecosystems. Science 319, 948-952.

Hanski, I., 1999. Metapopulation Ecology. Oxford University Press, Oxford, New York.

Hilborn, R., 2011. Future directions in ecosystem based fisheries management: A personal perspective. Fisheries Research 108, 235-239.

Hilborn, R., Walters, C.J., 1992. Quantitative fisheries stock assessment: choice, dynamics and uncertainty. Reviews in Fish Biology and Fisheries 2, 177-178. 
Horwood, J., 1993. The bristol Channel Sole (Solea solea (L.)) : A fishery case study. Advance in Marine biology 29, 215-367.

Houde, E.D., 2008. Emerging from Hjort's shadow. Journal of Northwest Atlantic Fishery Science 41, 53-70.

Hugues, B., Levey, M., Fountain, M., Carlisle, A., Chavez, F., Gleason, M. 2015. Climate mediates hypoxic stress on fish diversity and nursery function at the land-sea interface. Proceedings of the National Academy of Science, Early Edition 1505815112.

ICES. 2013. Report of the Working Group on the Assessment of Demersal Stocks in the North Sea and Skagerrak (WGNSSK), 24-30 April 2013, ICES Headquarters, Copenhagen. ICES Document CM 2013/ACOM:13. 1435 pp.

Iles, T.C., Beverton, J.H., 2000. The concentration hypothesis: the statistical evidence. ICES Journal of Marine Science 57, 216-227.

Jackson, J.B.C., Kirby, M.X., Berger, W.H., Bjorndal, K.A., Botsford, L.W., Bourque, B.J., Bradbury, R.H., Cooke, R., Erlandson, J., Estes, J.A., Hughes, T.P., Kidwell, S., Lange, C.B., Lenihan,

H.S., Pandolfi, J.M., Peterson, C.H., Steneck, R.S., Tenger, M.J., Warner, R.R., 2001.

Historical Overfishing and the Recent Collapse of Coastal Ecosystems. Science 293, 629-637.

Johnson, L.L., Sol, S.Y., Ylitalo, G.M., Hom, T., French, B., Olson, O.P., Collier, T.K., 1998. Reproductive injury in English sole (Pleuronectes vetulus) from the Hylebos Waterway, commencement Bay, Washington. Journal of Aquatic Ecosystem Stress and Recovery 6, 289-310.

Kotthaus, A., 1963. Tagging experiments with the North Sea sole (Solea solea) in 1959 and 1960. In Special Publication number 4 of the International Commission for the Northwest Atlantic Fisheries, pp. 123-129. Headquarters of the Commission, Darthmouth, Nova scotia, Canada.

Lehodey, P., Alheit, J., Barange, M., Baumgartner, T., Beaugrand, G., Drinkwater, K., Fromentin, J.M., Hare, S.R., Ottersen, G., Perry, R.I., Roy, C., Van der Lingen, C.D., Werner F., 2006. Climate variability, fish, and fisheries. Journal of Climate 19, 5009-5030.

Le Pape, O., Chauvet, F., Mahévas, S., Lazure, L., Guérault, G., Désaunay, Y. (2003). Quantitative description of habitat suitability for the juvenile common sole (Solea solea, L.) and contribution of different habitats to the adult population in the Bay of Biscay (France). Journal of Sea Research 50, 139-149.

Le Pape, O., Delavenne, J., Vaz, S., 2014. Quantitative mapping of fish habitat: A useful tool to design spatialised management measures and marine protected area with fishery objectives. Ocean and Coastal Management 87, 8-19.

Le Pape, O., Gilliers, C., Riou, P., Morin, J., Amara, R., Désaunay, Y., 2007. Convergent signs of degradation in both the capacity and the quality of an essential fish habitat: state of the Seine estuary (France) flatfish nurseries. Hydrobiologia 588, 225-229.

Le Pape, O., Bonhommeau, S., 2015. The food limitation hypothesis for juvenile marine fish. Fish and Fisheries. 16, 373-398.

Levin, P.S., Stunz, G.W., 2005. Habitat triage for exploited fishes: Can we identify essential 'Essential Fish Habitat?' Estuarine, Coastal and Shelf Science 64, 70-78.

Lindholm, J.B., Auster, P.J., Ruth, M., Kaufman, L., 2001. Modeling the effects of fishing and implications for the design of marine protected areas: juvenile fish responses to variations in seafloor habitat. Conservation Biology 15, 424-437.

Marchal, P., Desprez, M., Vermard, Y., Tidd, A., 2014. How do fishing fleets interact with aggregate extractions in a congested sea? Estuarine Coastal and Shelf Science 149, 168-177.

Parent, E., Rivot, E. (2012). Introduction to hierarchical bayesian modeling for ecological data. Chapman \& Hall/CRC.

Peterson, C.H., Grabowski, J.H., Powers, S.P., 2003. Estimated enhancement of fish production resulting from restoring oyster reef habitat: quantitative valuation. Marine Ecology Progress Series 264, 249-264.

Planque, B., Fromentin, J.M., Cury, P., Drinkwater, K.F., Jennings, S., Perry, R.I., Kifani, S., 2010. How does fishing alter marine populations and ecosystems sensitivity to climate. Journal of Marine Systems 79, 403-417. 
Portner, H., 2012. Integrating climate-related stressors effects on marine organisms: unifying principles linking molecule to ecosystem-level changes. Marine Ecology Progress Series 470, 273-290.

Punt, A. E., Hilborn, R. (1997). Fisheries stock assessment and decision analysis: the Bayesian approach. Reviews in Fish Biology and Fisheries, 7, 35-63.

Rabalais, N. 2015. Human impacts on fisheries across the land-sea interface. Proceedings of the National Academy of Science, Early Edition 1508766112.

Rijnsdorp, A.D., Pastoors, M.A., 1995. Modelling the spatial dynamics and fisheries of North Sea plaice (Pleuronectes platessa L.) based on tagging data. ICES Journal of Marine Science 52, 963-980.

Riou, P., Le Pape, O., Rogers, S.I., 2001. Relative contributions of different sole and plaice nurseries to the adult population in the Eastern Channel: application of a combined method using generalized linear models and a geographic information system. Aquatic living resources 14, $125-135$.

Rochette, S., Huret, M., Rivot, E., Le Pape, O., 2012. Coupling hydrodynamic and individual-based models to simulate long-term larval supply to coastal nursery areas. Fisheries Oceanography 21, 229-242.

Rochette, S., Le Pape, O., Vigneau, J., Rivot, E., 2013. A hierarchical Bayesian model for embedding larval drift and habitat models in integrated life cycles for exploited fish. Ecological Applications 23, 1659-1676.

Rochette, S., Rivot, E., Morin, J., Mackinson, S., Riou, P., Le Pape, O., 2010. Effect of nursery habitat degradation on flatfish population: Application to Solea solea in the Eastern Channel (Western Europe). Journal of Sea Research 64, 34-44.

Savina, M., Lunghi, M., Arcambault, B., Baulier, L., Huret, M., Le Pape, O., in review. Sole larval supply to coastal nurseries: interannual variability and connectivity at interregional and interpopulation scale. Journal of Sea research.

Seitz, R., Wennhage, H., Bergstrom, U., Lipcuis, R., Ysebaert, T., 2014. Ecological value of coastal habitats for commercially and ecologically important species. ICES Journal of Marine Science 71, 648-655.

Spies, I., Spencer, P.D., Punt, A.E., 2015. Where do we draw the line? A simulation approach for evaluating management of marine fish stocks with isolation-by-distance stock structure. Canadian Journal of Fisheries and Aquatic Sciences 72, 968-982.

Tuck, G., and Possingham, H., 1994. Optimal harvesting strategies for a metapopulation. Bulletin of Mathematical Biology 56(1), 107-127.

Turner, S.J., Thrush, S.F., Hewitt, J.E., Cummings, V.J., Funnell, G., 1999. Fishing impacts and the degradation or loss of habitat structure. Fisheries Management and Ecology 6, 401-420.

Van de Wolfshaar, K., HilleRisLambers, R., Gardmark, A., 2011. Effect of habitat productivity and exploitation on populations with complex life cycles. Marine Ecology Progress Series 438, 175-184.

Vasconcelos, R.P., Eggleston, D.B., Le Pape, O., Tulp, I., 2014. Patterns and processes of habitatspecific demographic variability in exploited marine species. ICES Journal of Marine Science $71,638-647$.

Worm, B., Barbier, E.B., Beaumont, N., Duffy, J.E., Folke, C., Halpern, B.S., Jackson, J.C.B., Lotze, H.K., Micheli, F., Palumbi, S.R., Sala, E., Selkoe, K.A., Stachowicz, J.J., Watson, R., 2006. Impacts of Biodiversity Loss on Ocean Ecosystem Services. Science 314, 787-790.

Yau, A.J., Lenihan, H.S., and Kendall, B.E., 2014. Fishery management priorities vary with selfrecruitment in sedentary marine populations. Ecological Applications 24(6), 1490-1504.

Ying, Y., Chen, Y., Lin, L., Gao, T., and Quinn, T., 2011. Risks of ignoring fish population spatial structure in fisheries management. Canadian Journal of Fisheries and Aquatic Science 68, 2101-2120. 
Table 1: Connectivity matrix (in proportion) from nursery (lines) to subpopulations (column) under the structural hypothesis $S_{0}$ (no inter-regional connectivity at age-2) and $S_{1}$ (including inter-regional connectivity at age-2)

\begin{tabular}{|c|c|c|c|c|c|c|}
\hline & \multicolumn{3}{|c|}{$S_{0}$ - No connectivity at age-2 } & \multicolumn{3}{|c|}{$S_{1}$ - With connectivity at age-2 } \\
\hline & West FR & $U K$ & East FR & West FR & $U K$ & East FR \\
\hline Seine & 1 & o & o & 0.8 & 0.1 & 0.1 \\
\hline Veys & 1 & o & o & 0.8 & 0.1 & 0.1 \\
\hline UK West & o & 1 & o & 0.1 & 0.8 & 0.1 \\
\hline Rye & o & 1 & o & 0.1 & 0.8 & 0.1 \\
\hline Somme & o & o & 1 & 0.1 & 0.1 & 0.8 \\
\hline
\end{tabular}


Table 2: Scenarios and associated modalities of stressors. For each of the three stressors, the "reference" option correspond to the one defined in the reference scenario (first line). The F values in the reference scenario correspond to the average estimated values in the last 4 years (2007-2011).

\begin{tabular}{|c|c|c|c|}
\hline \multirow[b]{2}{*}{ Investigated Effects } & \multicolumn{3}{|c|}{ Stressors } \\
\hline & $\begin{array}{l}\text { Hydrocgraphic } \\
\text { conditions }\end{array}$ & Habitat & Fishing \\
\hline Reference scenario $\boldsymbol{S c} \boldsymbol{e}_{\boldsymbol{r e f}}$ & Average & Unrestored Seine sector & $\begin{array}{c}F_{\text {WestFR }}=0.16 \\
F_{U K}=0.44 \\
F_{\text {EastFR }}=0.8\end{array}$ \\
\hline Hydrographic conditions & $\begin{array}{l}\text { Historical series } \\
(1982-2007)\end{array}$ & Reference & Reference \\
\hline Habitat & Reference & $\begin{array}{l}\text { Unrestored Seine sector } \\
\text { Restored surface area } \\
\text { Restored quality } \\
\text { Combined restoration }\end{array}$ & Reference \\
\hline Fishing & Reference & Reference & $F_{r}:$ o to 1.5 (step of 0.01$)$ \\
\hline $\begin{array}{l}\text { Hydrographic conditions } \mathrm{x} \\
\text { Fishing }\end{array}$ & $\begin{array}{l}\text { Historical series } \\
(1982-2007)\end{array}$ & Reference & $F_{r}:$ o to 1.5 (step of 0.01$)$ \\
\hline $\begin{array}{l}\text { Hydrographic conditions } \mathrm{x} \\
\text { Habitat }\end{array}$ & $\begin{array}{l}\text { Historical series } \\
(1982-2007)\end{array}$ & $\begin{array}{l}\text { Unrestored Seine sector } \\
\text { Restored surface area } \\
\text { Restored quality } \\
\text { Combined restoration }\end{array}$ & Reference \\
\hline Habitat $x$ Fishing & Reference & $\begin{array}{l}\text { Unrestored Seine sector } \\
\text { Restored surface area } \\
\text { Restored quality } \\
\text { Combined restoration }\end{array}$ & $\begin{array}{l}F_{r}: 0 ; \text { from } 0.15 \text { to } 0.30 \\
\text { (step of } 0.01 \text { ); } 0.5 ; 0.8 ; 2\end{array}$ \\
\hline "Best" scenario $\boldsymbol{S c} \boldsymbol{e}_{\text {best }}$ & year $=1993$ & Combined restoration & $\begin{array}{l}F_{r} \text { at } F_{M S Y}(0.2 \text { for all } \\
\text { subpopulations })\end{array}$ \\
\hline
\end{tabular}


Table 3: Marginal and combined impacts of stressors on selected indicators, all expressed as \%loss / gain with regard to the reference scenario except for the line No exploitation $/ \mathrm{F}_{\mathrm{MSY}}$ that refers to $\%$ gain/loss with regards to the $\mathrm{F}_{\mathrm{MSY}}$ scenario

\begin{tabular}{|c|c|c|c|c|c|}
\hline Details & Indicators & EC & West FR & UK & East FR \\
\hline \multicolumn{6}{|l|}{ Hydroclimatic conditions } \\
\hline \multirow{3}{*}{$\begin{array}{l}\text { Worst\&best hydrographic } \\
\text { conditions / Sce } \text { ref }\end{array}$} & $S S B_{e q}$ & $-34 /+8$ & $-12 /+7$ & $-60 /+11$ & $-31 /+7$ \\
\hline & $C_{e q}$ & $-26 /+6.5$ & $-12 /+7$ & $-60 /+11$ & $-31 /+7$ \\
\hline & Worst\&best years & $1991 / 1993$ & $2001 / 1982$ & $1991 / 1993$ & $1991 / 1992$ \\
\hline \multicolumn{6}{|l|}{ Habitat } \\
\hline \multirow{2}{*}{$\begin{array}{l}\text { Surface area restoration of Seine } \\
\text { estuary }\end{array}$} & $S S B_{e q}$ & +22 & +42 & - & \\
\hline & $C_{e q}$ & +12 & +42 & - & $=$ \\
\hline \multirow{2}{*}{$\begin{array}{l}\text { Quality restoration scenario of } \\
\text { Seine estuary }\end{array}$} & $S S B_{e q}$ & +7 & +13 & & - \\
\hline & $C_{e q}$ & +4 & +13 & & - \\
\hline \multirow{2}{*}{$\begin{array}{l}\text { Surface area \& quality } \\
\text { restoration of Seine estuary }\end{array}$} & $S S B_{e q}$ & +36 & +66 & & - \\
\hline & $C_{e q}$ & +20 & +66 & - & - \\
\hline \multicolumn{6}{|l|}{ Fishing } \\
\hline Exploitation at MSY & $S S B_{M S Y}$ & $\begin{array}{l}+96 \\
+32\end{array}$ & & +146 & $\begin{array}{l}+362 \\
+68\end{array}$ \\
\hline No exploitation & $S S B_{e q}$ & +470 & +158 & +616 & +1235 \\
\hline No exploitation / F $F_{M S Y}$ & $S S B_{e q}$ & +191 & +157 & +190 & +188 \\
\hline \multicolumn{6}{|l|}{ Cumulative } \\
\hline Best hydrographic conditions + & $S S B_{M S Y}$ & +131 & +42 & +155 & +384 \\
\hline $\begin{array}{l}\text { Surface area \& quality restoration } \\
+F_{M S Y}\end{array}$ & $C_{M S Y}$ & +59 & +73 & +34 & +68 \\
\hline
\end{tabular}




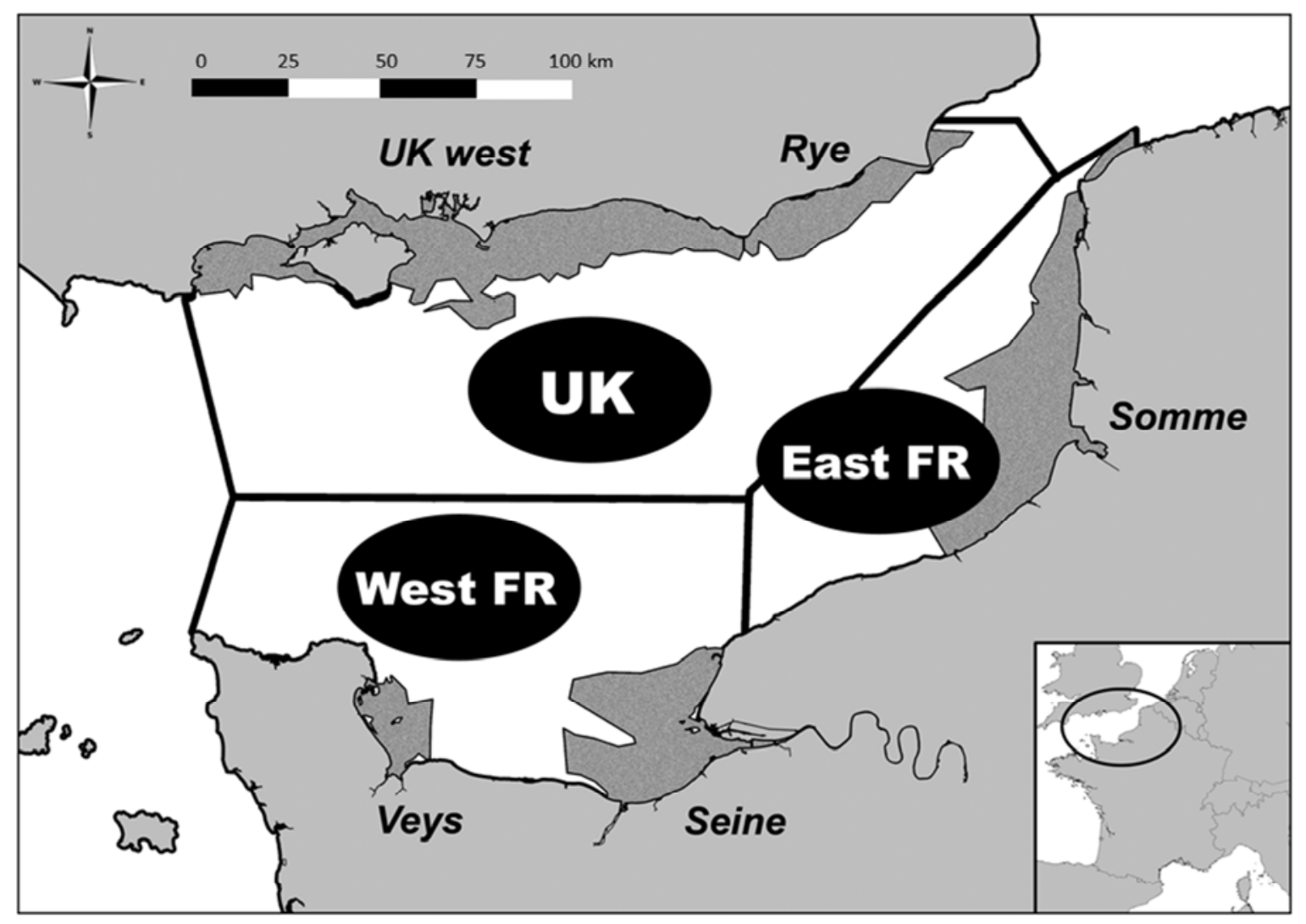




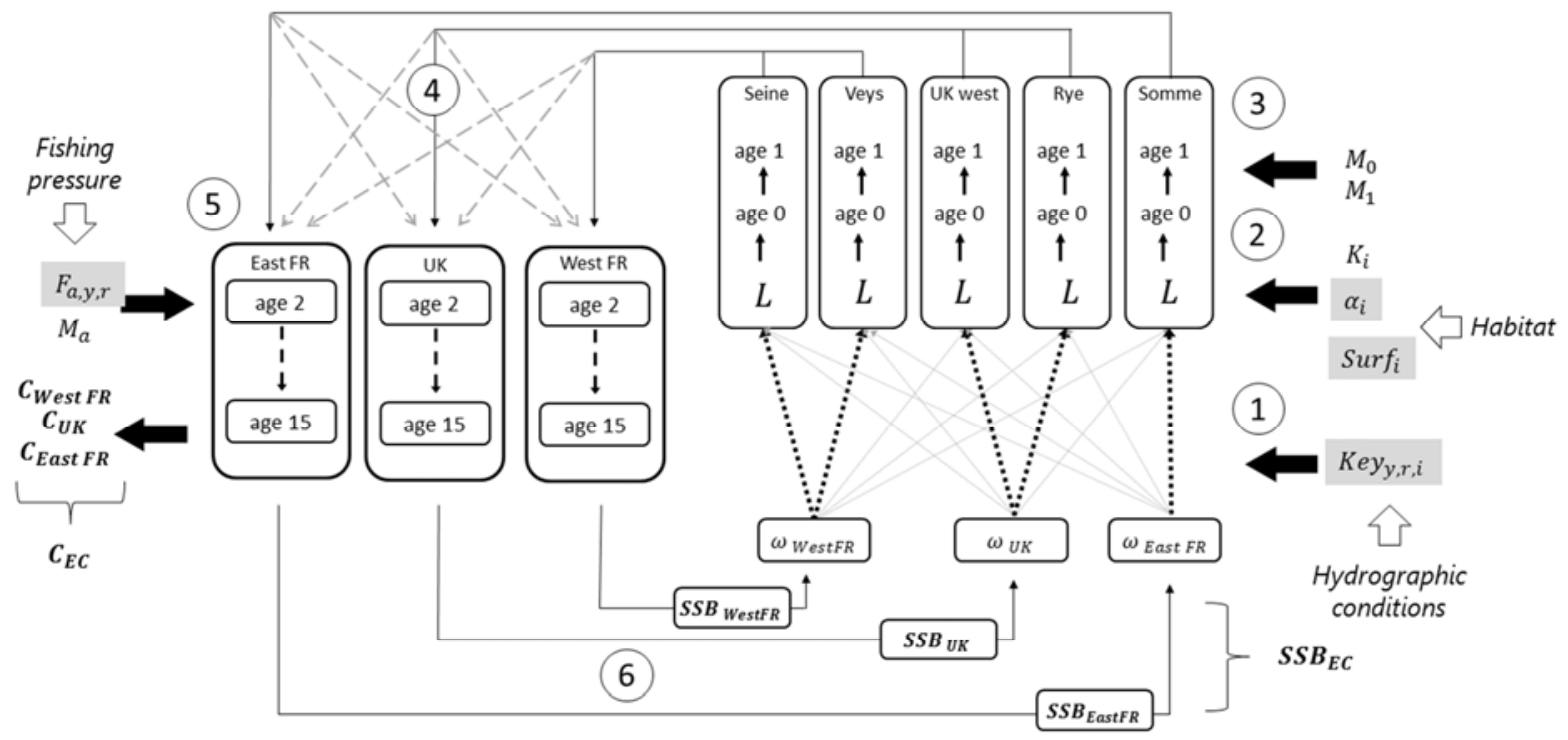




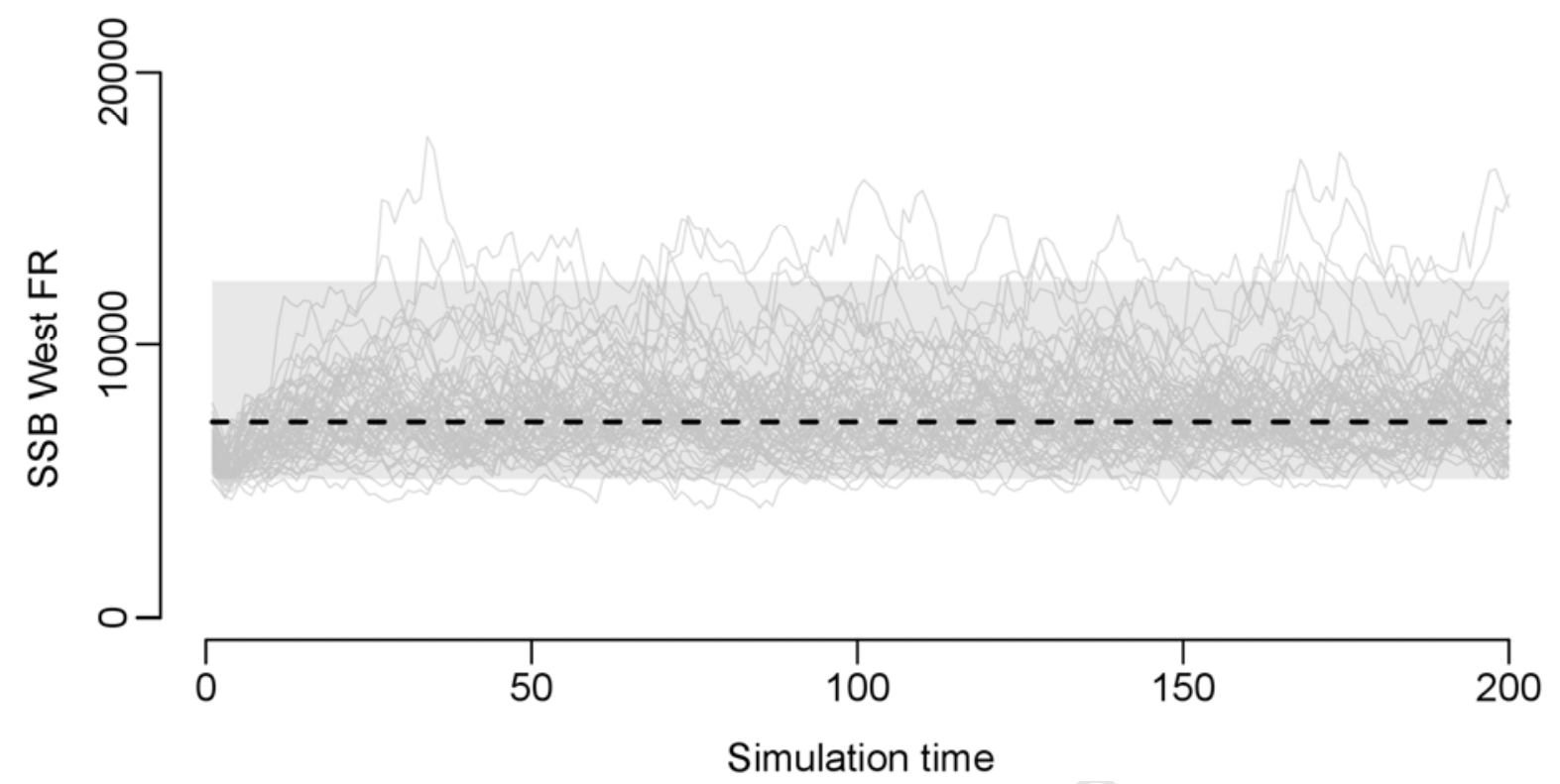




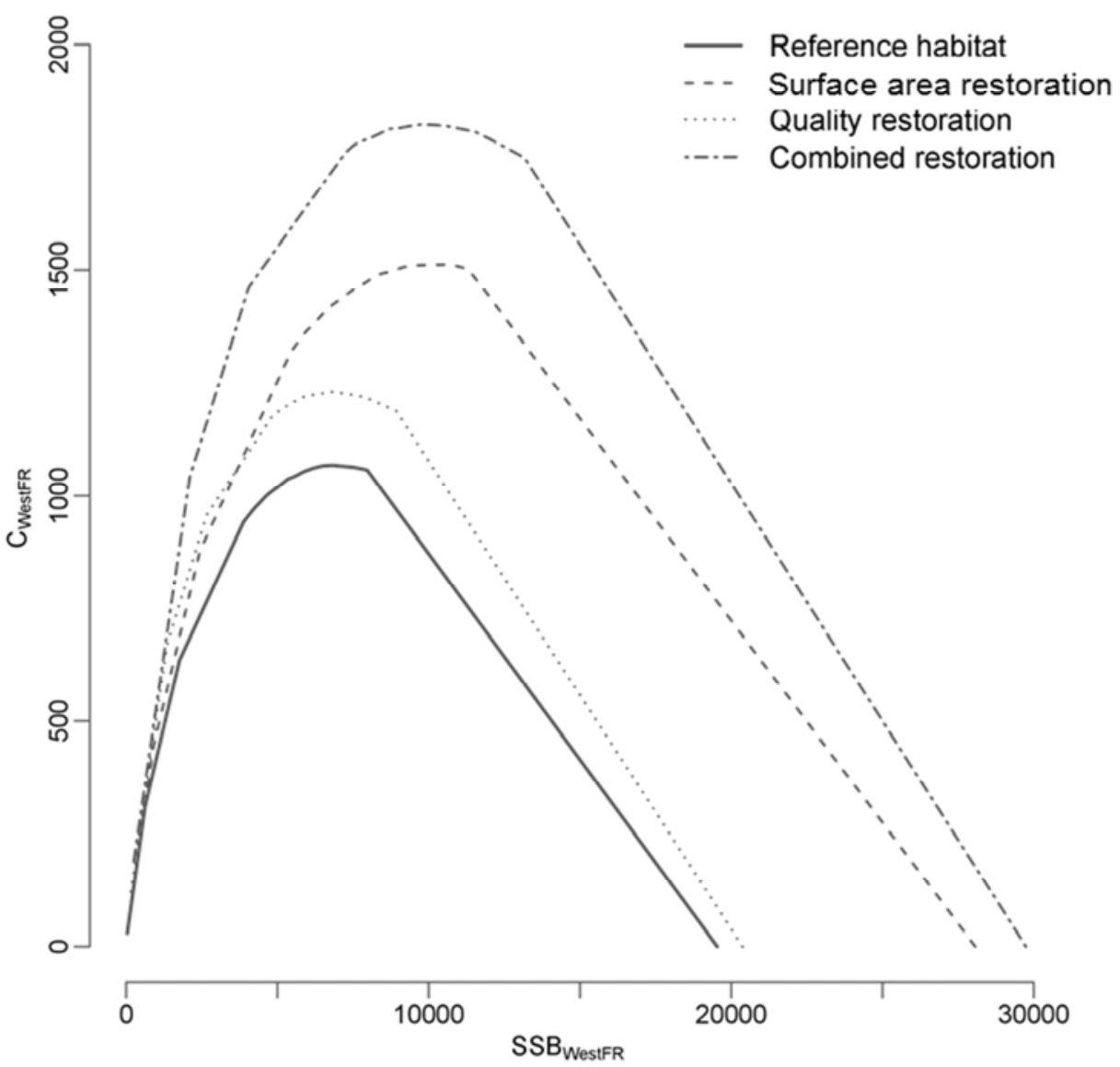




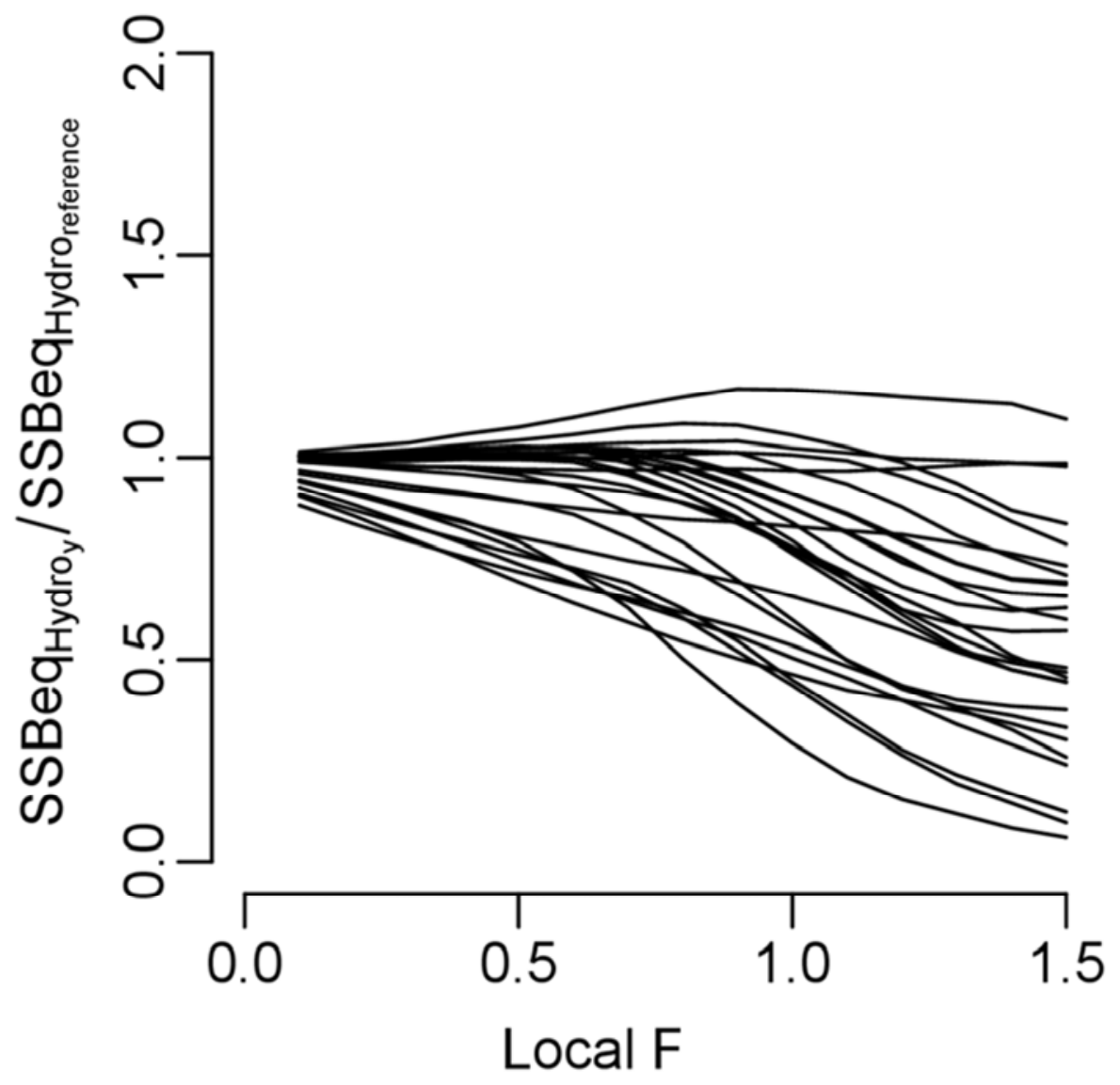




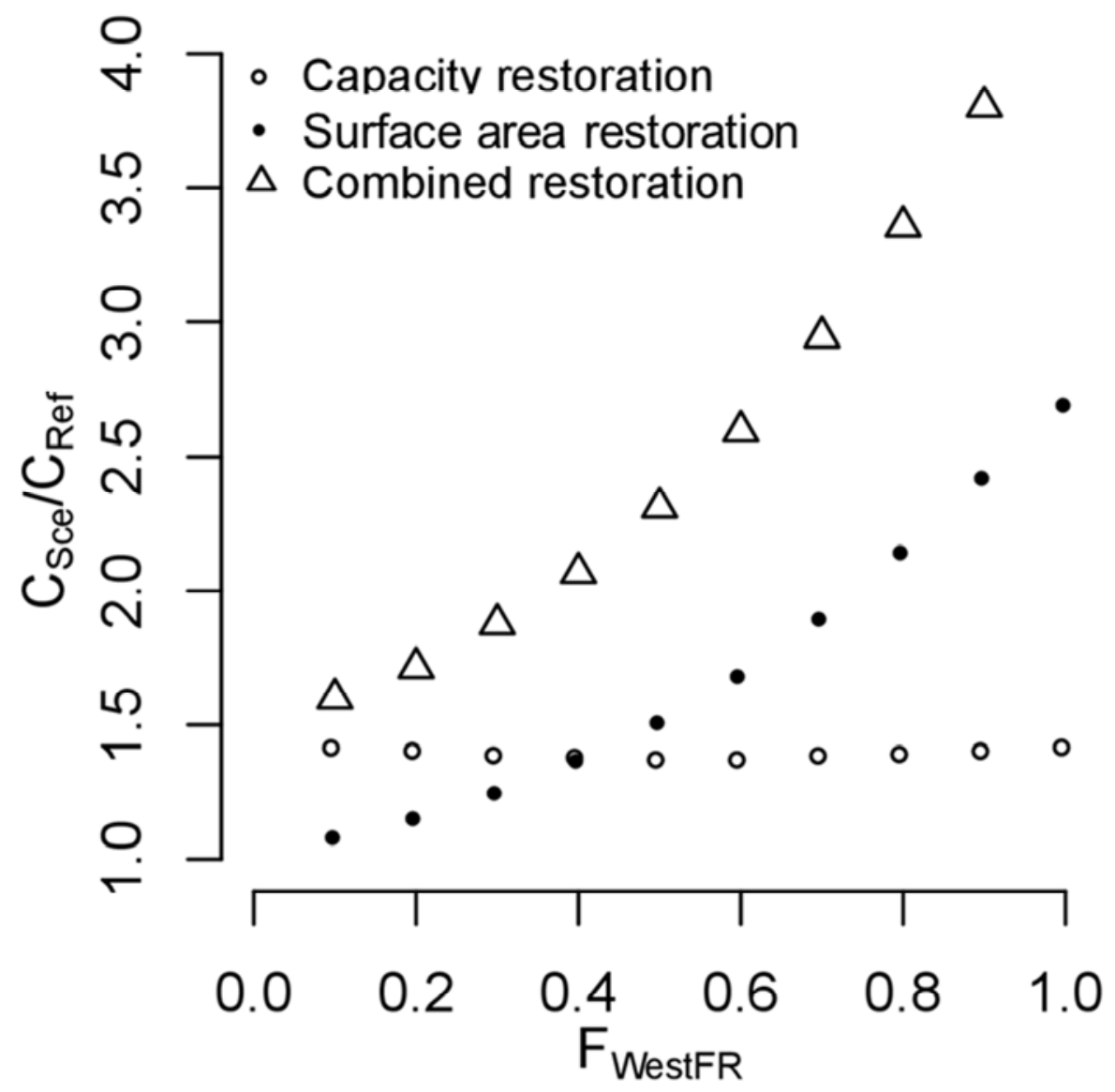




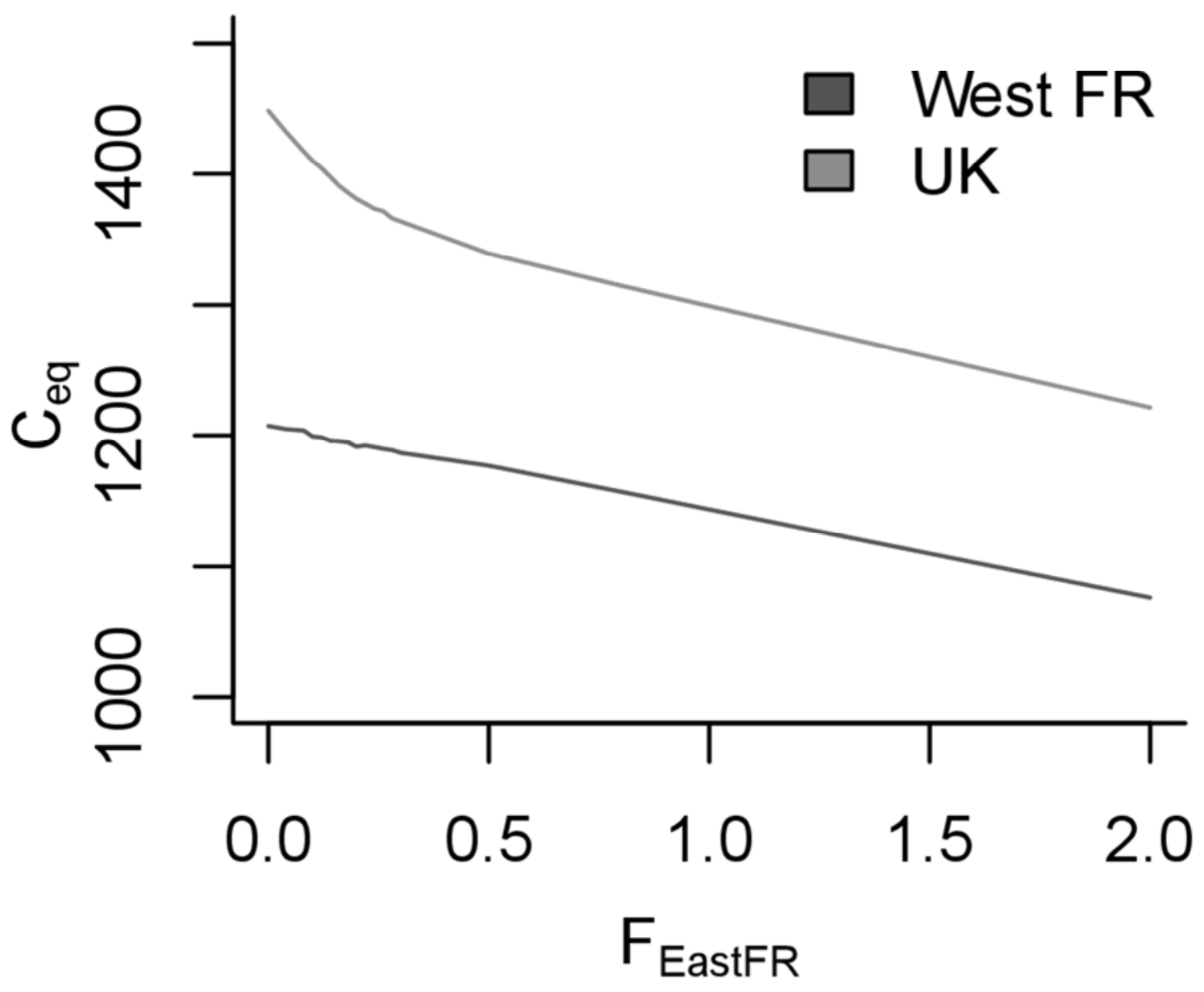




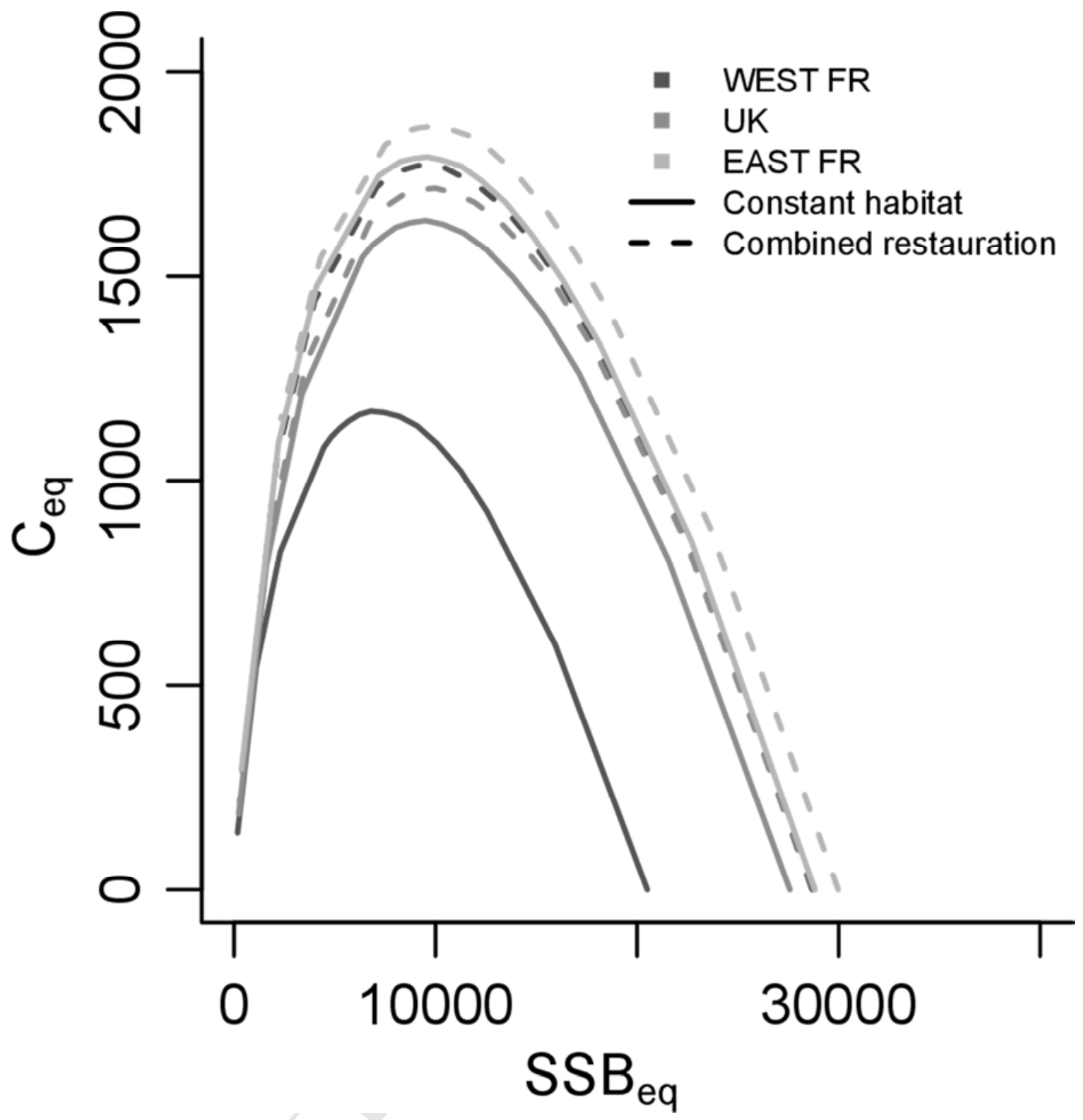

